\title{
A PSICOLOGIA NA FORMAÇÃO DO PEDAGOGO: ANÁLISE DAS DISCIPLINAS DE PSICOLOGIA DOS CURSOS DE PEDAGOGIA DE UNIVERSIDADES ESTADUAIS DO NORTE DO PARANÁ
}

\author{
Nathália Tavares Bellato Spagiari ${ }^{1}$, Maria Gabriela Montresol Sanches ${ }^{2}$, Mônica Tablas Martinez Figueiredo, \\ Maíra Bonafé Sei ${ }^{4}$, Rafael Bianchi Silva ${ }^{5}$ \\ ${ }^{1}$ Mestranda em Psicologia pela Universidade Estadual de Londrina - UEL, Londrina, PR. E-mail: nspagiari@gmail.com. \\ ${ }^{2}$ Mestranda em Psicologia pela Universidade Estadual de Londrina- UEL, Londrina, PR. \\ Mestranda em Psicologia pela Universidade Estadual de Londrina - UEL, Londrina, PR. Coordenadora do Núcleo de \\ Apoio Psicológico e Psicopedagógico da Faculdade da Alta Paulista de Tupã - FAP. \\ ${ }^{4}$ Doutora e pós-doutora em Psicologia Clínica pela Universidade de São Paulo - USP. Docente do Departamento de \\ Psicologia e Psicanálise da Universidade Estadual de Londrina, Londrina, PR. \\ ${ }^{5}$ Doutor em Educação pela Universidade Estadual Paulista - UNESP, Marília, SP. Docente do Departamento de \\ Psicologia Social e Institucional da Universidade Estadual de Londrina - UEL, Londrina PR.
}

\section{RESUMO}

Objetiva-se neste estudo refletir sobre a Psicologia no campo de formação de pedagogos e se esta tem sido oferecida enquanto ferramenta para uma educação emancipadora. Isto a partir da análise dos Projetos Político Pedagógicos (PPP) e dos programas de disciplinas da Psicologia do curso de Pedagogia ofertados nas universidades estaduais do Norte do Paraná. A partir disso, buscou-se analisar se a Psicologia empregada está implicada na formação de pedagogos com compromisso ético, social e reflexivo. Observouse uma variabilidade nas disciplinas e linhas teóricas da Psicologia ministradas na Pedagogia, como também, em conjunto com os objetivos e perfil do egresso contido nos PPP. Isto possibilitou maior amplitude do olhar profissional do pedagogo nos cursos analisados. Concluiu-se que a Psicologia pode favorecer o pensamento reflexivo na formação dos profissionais de Pedagogia, com temáticas que abordem a educação como processo complexo e multideterminado.

Palavras-chave: Planos de disciplina. Projeto político pedagógico. Pedagogia. Disciplinas de Psicologia.

\section{PSYCHOLOGY IN PEDAGOGY FORMATION: ANALYSIS OF THE DISCIPLINES OF PSYCHOLOGY OF THE COURSES OF PEDAGOGY OF STATE UNIVERSITIES OF THE NORTH OF PARANÁ}

\begin{abstract}
The objective of this study is to reflect on Psychology in the field of pedagogical training and whether it has been offered as a tool for an emancipatory education. This is based on the analysis of the Pedagogical Political Projects (PPP) and the Psychology courses of the Pedagogy course offered at the state universities of the North of Paraná. From this, we sought to analyze if the psychology employed is involved in the formation of pedagogues with ethical, social and reflexive commitment. It was observed a variability in the disciplines and theoretical lines of Psychology taught in Pedagogy, as well as in conjunction with the objectives and egress profile contained in the PPP. This allowed for a greater breadth of the professional view of the pedagogue in the courses analyzed. It was concluded that Psychology can favor reflective thinking in the training of Pedagogy professionals, with themes that approach education as a complex and multi-determined process.
\end{abstract}

Key words: Discipline plans. Political pedagogical project. Pedagogy. Disciplines of Psychology.

\section{INTRODUÇÃO}

A formação do pedagogo perpassa diferentes áreas do conhecimento que se entrelaçam e direcionam sua prática cotidiana.
Um desses saberes refere-se à Psicologia. Esta pode contribuir para o trabalho do pedagogo desde as teorias que discorrem sobre o desenvolvimento humano e o processo ensino- 
aprendizagem, como na promoção de uma reflexão crítica sobre a educação, como fenômeno complexo e determinado por diversos fatores interdependentes.

Para tanto, problematizar os conhecimentos de Psicologia que são transmitidos para os futuros pedagogos incide numa visão crítica da própria Psicologia e de sua relevância no curso de Pedagogia. Como propõe Saviani (2009), o trabalho de formação educação - deve ser pensado como instrumento que capacita o indivíduo à mudança social. No que tange à contribuição da Psicologia, isto é possível ao se considerar a ciência psicológica como disciplina implicada na formação de educadores com compromisso ético e social, abordando temas cuja finalidade seja a de ampliar o olhar sobre a educação como processo multideterminado. Para tanto, deve-se levar em conta o contexto social, histórico, político e cultural para o desenvolvimento de sujeitos autônomos, protagonistas de sua própria história, a partir do ensino.

Nessa direção, por intermédio da educação, visa-se desenvolver um sujeito reflexivo, preparado para execução de trabalhos e o agir cidadão, possibilitando indivíduos que, além de dominar conhecimentos, encontram-se aptos a fazer parte de um sistema político de maneira reflexiva. Logo, a educação tem o potencial de constante reformulações de suas práticas de acordo com o contexto histórico e social no qual o sujeito se encontra (VEIGA, 2003).

A educação é formativa e marca de um povo e de uma cultura. É a partir da educação que se mantém valores e práticas que estão instituídas na sociedade. Pode servir para reproduzir o que está instituído, como também para transformá-lo - ampliar o pensamento crítico e reflexivo - e desenvolver outras subjetividades. Não há apenas um modelo de educação, nem a educação ocorre só no ambiente formal com a figura do professor dotado de um saber especializado (BRANDÃO, 1981).

Observa-se que existem múltiplas concepções a respeito da educação, envolvendo seus fundamentos e seus fins, além de interesses econômicos, políticos que a atravessam. Assim, há diferenças na compreensão acerca do que é o ato de ensinar, o que o determina e, finalmente, a que e a quem ele serve. Diante disto,
[...] do ponto de vista de quem a controla, muitas vezes definir a educação e legislar sobre ela implica justamente ocultar a parcialidade destes interesses, ou seja, a realidade de que eles servem a grupos, a classes sociais determinadas, e não tanto "a todos", "à Nação", "aos brasileiros". Do ponto de vista de quem responde por fazer a educação funcionar, parte do trabalho de pensá-la implica justamente em desvendar - que faz com que a educação, na realidade, negue e renegue o que oficialmente se afirma dela na lei e na teoria (BRANDÃO, 1981, p. 27).

Neste sentido, a importância dessa discussão e do papel emancipatório que a educação pode assumir alude à proposição de indagações ético-sociais na educação formal, discussão esta que pode ser incorporada no currículo do pedagogo, pela Psicologia, a fim de que haja superação da lógica pautada na racionalidade técnica e da reprodução acrítica de conhecimentos. Fomenta-se, assim, o desenvolvimento pleno e a constituição de cidadãos, como se supõe na Lei de Diretrizes e Bases da Educação Nacional (BRASIL, 2017).

Ainda que existam outros lugares de formação educativa que vão além da escola, como em família, grupos sociais, instituições, dentre outros ambientes fornecedores de conhecimento (LIBÂNEO, 2006), os parâmetros que irão subsidiar e objetivar o ensino de um determinado conhecimento para um contexto específico estão sintetizados no Projeto Político Pedagógico (PPP) da instituição educativa.

Os Projetos Políticos Pedagógicos trazem conteúdos instituídos socioculturalmente e, para compreender politicamente esses projetos, devese recorrer à análise dos pressupostos que embasam sua concepção e se estão constituídos como instrumentos apenas de controle e regulação (VEIGA, 2003). A efetividade do processo educativo necessita da orientação sobre seus objetivos e formas de execução e, para isto, a Pedagogia se constitui "como teoria e prática 
do processo educativo" (LIBÂNEO, 2006, p. 23), projetando indivíduos atuantes dentro de um determinado contexto. Portanto, a prática educativa contém cunho pedagógico "como ação consciente, intencional, e planejada no processo de formação humana, através de objetivos e meios estabelecidos por critérios socialmente determinados" (LIBÂNEO, 2006, p. 24) apontando um modelo de homem a ser desenvolvido em sociedade.

Como a Psicologia e a educação ficaram atreladas uma a outra ao longo da história, sendo que a Psicologia passou a orientar as práticas educativas ao ser inserida como disciplina obrigatória no currículo do curso de formação do pedagogo, considera-se que pode, então, contribuir com a promoção de uma educação inclusiva e emancipatória, se os conhecimentos psicológicos forem bem articulados e contextualizados. Entretanto, as teorias e concepções psicológicas são diversificadas e introduzidas de maneira segmentada e aligeirada na Pedagogia, chamadas a orientar a postura pedagógica e favorecer a aprendizagem dos alunos (COSTA, 2015).

As teorias e técnicas psicológicas utilizadas e interpretadas de forma fragmentada no sistema educacional correm o risco de correlacionar os processos pedagógicos e seus problemas apenas como questões de natureza psicológica, o que contribui para uma visão que responsabiliza a criança e sua família pelos problemas e dificuldades no desempenho escolar. Esse enfoque reducionista acaba "desprezando o processo educativo como totalidade multideterminada, relegando a segundo plano, ou omitindo, fatores de natureza histórica, social, cultural, política, econômica e, sobretudo, pedagógica na determinação do processo educativo" (ANTUNES, 2008, p. 472).

Sobre esse ponto, Patto (2005) expõe que é necessário cuidar das agressões que perpassam as práticas e processos diários de ensino, uma vez que a própria política educacional gera mais autoritarismo, arbitrariedade e violência, porque reproduz na escola as relações de desigualdade que são perpetradas na sociedade. A autora considera que a situação escolar só será revertida quando os educadores forem valorizados e sua formação seja centrada na reflexão crítica sobre a realidade social.

Entende-se que a Psicologia, no curso de Pedagogia, pode auxiliar na viabilização da formação de cidadãos por meio da educação.
Para tanto, ela deve ser pensada na formação do pedagogo como uma disciplina que

[...] só se efetiva à medida
que supere o plano teórico
e enfrente as
problemáticas
demandadas da prática
escolar. Isso significa dizer,
que não será a mera
apropriação dos
conhecimentos, conceitos
e ideias psicológicas e
consequente tentativa de
aplicação dos mesmos, em
quaisquer contextos, que
alcançarão resultados,
pelo contrário, é preciso
se considerar todo o
contexto envolvido numa
determinada situação-
problema, para que todos
os aspectos sejam
considerados e, se tenha a
possibilidade de uma
intervenção adequada -
uso correto desses
conhecimentos (COSTA,
2015 , p. 98-99).

Partindo destes pressupostos aqui levantados, este estudo tem finalidade de descrever como a Psicologia se apresenta na formação do pedagogo - em universidades estaduais localizadas na região Norte do Paraná - a partir dos PPP e das ementas, de forma a capacitar profissionais com uma visão mais reflexiva sobre sua prática formativa e atuação educacional.

\section{Um pouco de história: imbricações da Psicologia com a Pedagogia}

De acordo com Lima e Catani (2015), em meados de 1930, a Psicologia passou a ser ministrada nos cursos de formação docente orientando-se a partir da perspectiva científica cujo objetivo seria de formular orientações práticas para educação de crianças e adolescentes. Posteriormente, foram desenvolvidos estudos pedagógicos atrelados ao desenvolvimento infantil.

Segundo os autores, logo, a Pedagogia apropriou-se da Psicologia enquanto possibilidade de compreender a personalidade e as diferenças individuais dos alunos, assim como elas se manifestavam nas instituições escolares. O foco nas diferenças individuais promoveu 
práticas e discursos que justificavam a classificação e segregação de alunos, como forma de favorecer o desenvolvimento dos mesmos. Desta forma, a introdução da Psicologia dentro do campo pedagógico orientaria as metodologias de ensino, favorecendo a aprendizagem a partir das particularidades de cada aluno.

Em uma segunda fase, por volta da década de 1960, houve aumento expressivo das pesquisas científicas e empíricas e a Psicologia foi fortemente influenciada pelo positivismo. Neste período foram construídas as bases para 0 reconhecimento da Psicologia enquanto ciência e profissão, além disso foi um momento marcado pela abertura de cursos de graduação em Psicologia. Deste período em diante, a Psicologia dentro da Pedagogia esteve atrelada ao estudo do fracasso escolar e das doenças mentais, influenciadas a partir das teorias de Piaget e Vygotsky, estudos que são ainda vigentes na atualidade (COSTA, 2015; PETERNELLA; GALUCH, 2011).

No cenário internacional e histórico, houve uma preocupação em tornar a ação pedagógica baseada nas técnicas científicas, conforme o pensamento positivista vigente. Foi o filósofo Herbart, no século XIX, que alicerçou a princípio o pensamento pedagógico com a Psicologia, que já dispunha de técnicas científicas, como uma possibilidade positivista e racional de se pensar a educação. Este mesmo teórico criticou o postulado que considerava as faculdades mentais como inatas na compreensão do psiquismo, pensamento vigente na educação tradicional clássica. Foi apenas no final do mesmo século que Dewey, filósofo americano e crítico de Herbart, desenvolveu uma diferente concepção de homem a partir da ideia da articulação entre experiência, vida e educação. Neste sentido, considerou também que a escola se articulava com o mundo externo a ela, ou melhor, com o universo do educando. Para tanto, a escola para a existir em função dos alunos que a frequentavam, sendo atribuído o papel de possibilitar o desenvolvimento do pensamento reflexivo destes (PEREIRA et al, 2009).

Outros autores continuaram o processo de tentar validar a Pedagogia cientificamente. Por exemplo, o teórico Edouard Claparèd considerava que apenas a Psicologia poderia dar fundamento científico à Pedagogia, sendo necessário o estudo das manifestações naturais do infante, que deveriam ser feitos por meio de pesquisas científicas, o que exigia uma preparação específica dos futuros educadores. Foi em 1920 que o pensador criou o instituto Jean Jacques Rousseau, no intuito de ser uma escola de ciências da educação. Para Claparèd, a inteligência deveria ser considerada um instrumento de adaptação quando o instinto e o hábito falham, desta forma, a individualidade seria reduzida às diferentes aptidões individuais. Neste sentido, o professor deveria ser um estimulador de interesses, com a função de organizar o ambiente para 0 despertar das funções intelectuais e sociais da criança (CARVALHO, 2002).

Foi por meio das influências dos pensamentos de Claparède que Jean Piaget desenvolveu pesquisas para compreender o desenvolvimento infantil, tendo em vista como o sujeito constrói o conhecimento (COLINVAUX; BANKS-LEITE, 2012). Para Piaget, o indivíduo estaria sujeito aos fatores psicogênicos, que abarcaria o sistema nervoso e mecanismos psíquicos, e ao meio físico. O desenvolvimento da inteligência seria a partir de uma sucessão de estágios nos processos educativos, com isso, a aprendizagem estaria subordinada às estruturas de pensamento construídas pela criança, compreendidos como maturação. Desta maneira, o professor promoveria o desafio da reflexão, e para isso, seria necessário o conhecimento dos estágios do desenvolvimento cognitivo (LIMA, 1990).

Foi neste cenário de busca por cientificidade da Pedagogia que Vygotsky delimitou o que chamou de crise da Psicologia, para as tentativas elementares de explicação de fenômenos psicológicos. Para ele, a superação dessa crise metodológica seria possível apenas com uma metodologia de embasamento histórico, fundamentada no método dialético (ASBAHR, 2005). Além de sua crítica à metodologia vigente, o autor propôs também a compreensão do desenvolvimento humano a partir da perspectiva histórico-cultural, ou seja, considerando os modos de pensar, agir e sentir produzidos pelo social num determinado tempo histórico (VYGOTSKY,1929).

A partir de Engels, o autor realiza uma discussão sobre 0 trabalho enquanto humanizador e facilitador do desenvolvimento cultural. Desta forma, o sujeito ao transformar a natureza externa por meio do trabalho construído com recursos internos, transformaria também seu interior. Logo, os fenômenos psíquicos seriam sociais em sua origem. É neste 
cenário que se compreende que o sujeito aprende na relação com o outro, destacando-se então a importância da interação. Assim, se pode concluir que, na perspectiva de Vygotsky, a cultura aparece como elemento constitutivo do ser humano (LIMA, 1990).

Historicamente, a Psicologia dentro da Pedagogia foi marcada por temáticas referentes à aprendizagem e à compreensão das fases do desenvolvimento humano. Desde o século XIX, a Psicologia desenvolveu concepções teóricas com finalidade de alcançar os objetivos pedagógicos formais. Para isso, buscando o reconhecimento de sua cientificidade, os conhecimentos psicológicos auxiliavam no ajustamento dos indivíduos à uma estrutura educacional, proporcionando a compreensão dos fenômenos do desenvolvimento e educacionais, além de auxiliar na resolução de problemas (COSTA, 2015). No entanto, há a necessidade de avaliar os conceitos difundidos atualmente, além dos valores sociopolíticos envolvidos na disseminação de conteúdo. Como aponta Souza (2009, p.181),

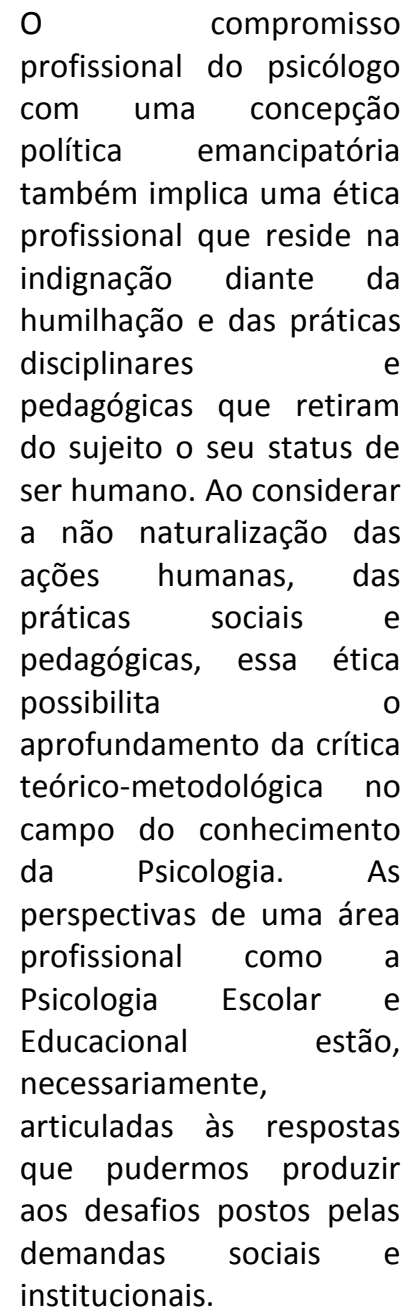

Por esta via, é imprescindível compreender as concepções ideológicas e contextualizá-las à realidade do sujeito, se estão possibilitando sua emancipação levando-o à reflexão ou se se restringem à replicação de conteúdos (LIBÂNEO, 2006). Destarte, pensar a prática pedagógica implica em analisar o que é relevante para a formação do futuro profissional pedagogo, qual o papel da Psicologia nessa formação, se é inserido no seu bojo abordagens mais críticas da Psicologia da educação, disparadoras da problematização e da clarificação dos mecanismos e entraves sociopolíticos ocultos nas práticas disseminadas nos ambientes educacionais.

Há implicações ao se definir um currículo, uma vez que podem provocar efeitos na prática pedagógica enquanto formadoras da consciência de estudantes e sua influência na organização social. Geralmente, tem-se buscado a manutenção de modelos pedagógicos tradicionais ao invés de se priorizar o desenvolvimento da autonomia de pensamento dos alunos. Como resultado se tem colhido processos educativos despidos de seus aspectos ideológicos e políticos, ou seja, vazios de sentido (MOREIRA, 1997).

Por fim, a formação profissional deve promover a instrumentalização de indivíduos conscientes a fim de que promovam a transformação das circunstâncias e de si mesmos, só a partir de então pode-se considerar a educação como emancipadora (MARTINS, 2011). Neste sentido, cabe a reflexão sobre a proposta de Psicologia no campo de formação de pedagogos, se esta tem sido oferecida enquanto ferramenta para uma educação emancipadora.

\section{MÉTODO}

Esta pesquisa é pautada na análise documental de acordo com as proposições de Cechinel, Fontana, Giustina, Pereira e Prado (CECHINEL et al, 2016) e se baseou no método adotado por Alves (2016). Tal pesquisadora utilizou os PPP e as disciplinas de Psicologia dos cursos de Pedagogia de universidades estaduais do Paraná com objetivo de mapear como a Psicologia vem discutindo especificamente o tema da "(a)normalidade" em tal contexto.

$\mathrm{Na}$ pesquisa realizada por Alves (2016), a coleta foi elaborada por uma busca e análise de uma série de dados sobre as disciplinas de Psicologia contidas nos PPP e planos de disciplina das disciplinas. Entre os dados levantados encontram-se quais as disciplinas de Psicologia 
ofertadas, ano do curso, objetivo da disciplina, conteúdos ministrados e referências utilizadas.

No que tange esta pesquisa, os instrumentos utilizados para a coleta de dados foram os PPP e os planos das disciplinas de Psicologia contidas no curso de Pedagogia das universidades estaduais do Norte do Paraná. Buscou-se inicialmente estes materiais por meio dos sites das instituições, entretanto, notou-se a ausência dos planos de disciplina. Devido a essa dificuldade, entrou-se em contato - através de email e telefonemas - com as instituições de ensino, convidando-as a participarem da pesquisa. Após a aceitação da instituição, requisitou-se os planos de disciplina que abordassem especificamente a temática da Psicologia.

Entre as disciplinas cujos programas foram enviados pelas universidades, selecionouse as que entraram no critério estabelecido para a pesquisa. $O$ critério de inclusão foi utilizar as disciplinas que contivessem o termo "Psicologia" em seu nome e, descartadas todas as demais disciplinas que não atenderam ao critério de inclusão.

Para esta pesquisa, os dados utilizados foram retirados dos PPP de cada universidade e depois relacionados com informações dos planos das disciplinas de Psicologia entre eles para sua análise. Posteriormente, com base em pesquisadores dos campos da Psicologia, Pedagogia e Educação analisou-se se os planos de disciplina oportunizaram os pressupostos da Pedagogia, enquanto formadora de profissionais com pensamento reflexivo sobre a educação e que conduzam a uma emancipação dos atores que participam do contexto educacional.

Ao fim do processo, buscou-se analisar quais conteúdos são ministrados, assim como quais perspectivas sobre a Psicologia estão sendo abordadas em seus planos de disciplina, e, como a Psicologia tem contribuído na formação do pedagogo. Além disso, discutiu-se se há na bibliografia das disciplinas a inserção de temáticas da Psicologia da educação que possibilitem a reflexão sobre a atuação do pedagogo e seu contexto educacional.

\section{RESULTADOS}

A partir dos critérios de inclusão, como também, do sigilo garantido às universidades que ofertam o curso de Pedagogia, estas foram renomeadas para o estudo. Atribuiu-se siglas U1 a U6, com o objetivo de proceder de forma ética, para que a análise se restrinja aos dados coletados nos documentos e sem enfoque para determinada instituição.

No quadro I, observa-se a quantidade de disciplinas que atenderam os critérios de inclusão para a análise deste estudo por instituição. A U6 encaminhou 6 planos de aula que consideraram de Psicologia, contudo, não possuem esta nomenclatura em seu título e não abordam a Psicologia de forma direta. Logo, 4 planos de disciplina foram descartados para análise dos dados. Assim, nota-se que há uma variação de 2 a 5 disciplinas ofertadas dependendo da universidade.

Quadro I. Quantidade de disciplinas de Psicologia ofertadas nos cursos de Pedagogia em universidades estaduais do Norte do Paraná.

\begin{tabular}{|c|c|c|c|c|c|c|}
\hline Universidades & U1 & U2 & U3 & U4 & U5 & U6 \\
\hline Número de disciplinas sobre psicologia & 5 & 4 & 2 & 2 & 2 & 2 \\
\hline
\end{tabular}

Fonte: Autor (2018).

Os dados coletados nos PPP e nos programas das disciplinas de Psicologia nos cursos de Pedagogia das universidades do Norte do Paraná foram analisados por eixos temáticos divididos em: Perspectivas e correntes teóricas da Psicologia e, o outro eixo, Conteúdos ministrados nas disciplinas - a partir das temáticas disparadas pelas bibliografias selecionadas. Logo, foram analisadas as disciplinas e suas bibliografias que serão citadas ao longo dos resultados para facilitar o cruzamento dos dados. As referências bibliográficas e objetivos da disciplina foram retiradas dos planos de disciplina de cada uma aqui mencionada.

\section{Perspectivas e correntes teóricas da Psicologia}

Pode-se observar no quadro II que a maioria das instituições estudadas disponibilizou em sua grade curricular a disciplina "Psicologia da Educação", com exceção da U6. Logo, entende-se as instituições parecem proporcionar ao aluno competências para que este se desenvolva de maneira técnico e profissional. 
Quadro II. Disciplinas de Psicologia ofertadas nos cursos de Pedagogia em universidades estaduais do Norte do Paraná.

\begin{tabular}{|c|c|c|c|c|c|c|}
\hline Universidades & U1 & U2 & U3 & U4 & U5 & U6 \\
\hline \multirow{5}{*}{$\begin{array}{l}\text { Disciplinas } \\
\text { (Ano do curso) }\end{array}$} & $\begin{array}{l}\text { Psicologia da } \\
\text { Educação: } \\
\text { Aspectos } \\
\text { Neuropsicológi } \\
\text { cos e Afetivos } \\
\text { (1 ano) }\end{array}$ & $\begin{array}{l}\text { Psicologia da } \\
\text { Educação I } \\
\text { (Ano não } \\
\text { identificado) }\end{array}$ & $\begin{array}{l}\text { Psicologia } \\
\text { da } \\
\text { Educação I } \\
\text { (10 ano) }\end{array}$ & $\begin{array}{l}\text { Psicologia } \\
\text { da } \\
\text { Educação I } \\
\text { (10 ano) }\end{array}$ & $\begin{array}{l}\text { Psicologia da } \\
\text { Educação: } \\
\text { Aprendizagem } \\
\text { (1ㅇano) }\end{array}$ & $\begin{array}{c}\text { Psicologia do } \\
\text { Desenvolvimento } \\
\text { B } \\
\left(2^{\circ} \text { ano }\right)\end{array}$ \\
\hline & $\begin{array}{l}\text { Psicologia da } \\
\text { Educação: } \\
\text { Abordagens } \\
\text { Humanista e } \\
\text { Epistemologia } \\
\text { Genética } \\
\text { (1 ano) }\end{array}$ & $\begin{array}{c}\text { Psicologia da } \\
\text { Educação II } \\
\text { (Ano não } \\
\text { identificado) }\end{array}$ & $\begin{array}{l}\text { Psicologia } \\
\text { da } \\
\text { Educação II } \\
\text { (2o ano) }\end{array}$ & $\begin{array}{l}\text { Psicologia } \\
\text { da } \\
\text { Educação II } \\
\text { (2o ano) }\end{array}$ & $\begin{array}{l}\text { Psicologia da } \\
\text { Educação: } \\
\text { Desenvolviment } \\
\text { o Humano } \\
\text { (2 ano) }\end{array}$ & $\begin{array}{c}\text { Psicologia da } \\
\text { Aprendizagem A } \\
\text { (3o ano) }\end{array}$ \\
\hline & $\begin{array}{c}\text { Psicologia da } \\
\text { Educação: } \\
\text { Temáticas da } \\
\text { vida } \\
\text { contemporânea } \\
\text { (2º ano) - semi- } \\
\text { presencial }\end{array}$ & $\begin{array}{c}\text { Psicologia da } \\
\text { Educação III } \\
\text { (Ano não } \\
\text { identificado) }\end{array}$ & & & & \\
\hline & $\begin{array}{l}\text { Psicologia da } \\
\text { Educação: } \\
\text { Abordagens } \\
\text { Comportament } \\
\text { al e Histórico- } \\
\text { Cultural (2 } \\
\text { ano) }\end{array}$ & \multirow{2}{*}{$\begin{array}{c}\text { Psicologia da } \\
\text { Educação IV } \\
\text { (Ano não } \\
\text { identificado) }\end{array}$} & & & & \\
\hline & $\begin{array}{l}\text { Psicologia da } \\
\text { Educação: } \\
\text { Abordagem } \\
\text { Walloniana } \\
\text { (3o ano) }\end{array}$ & & & & & \\
\hline
\end{tabular}

Fonte: Autor (2018).

Segundo Costa (2005), o objetivo da formação na maioria das vezes é adequar o futuro professor às demandas do mercado, as quais contemplam uma postura individualista do sujeito, que não refletem o processo educacional, mas que se debruçam meramente à aprendizagem, desconsiderando assim o processo de fragmentação e o oferecimento de conteúdos descontextualizados. Conforme a trajetória histórica, os professores eram formados para atuarem apenas em nível prático. Assim, o intuito era uma formação que somente abordasse as metodologias e técnicas de aprendizagem. Aspecto que pode ser observado com a apresentação da Psicologia e seu leque de abordagens na formação do profissional pedagogo, como exposto nas universidades abaixo.
$\mathrm{Na}$ instituição nomeada como $\mathrm{U} 1$, se observa o oferecimento de várias disciplinas da área de Psicologia, o que potencializa maior disseminação dos conhecimentos, como também, percebe-se multiplicidade de temáticas da Psicologia. Este dado pode ser associado ao perfil do egresso, apontado no PPP de U1, que aponta a formação de um profissional que possa atuar no meio social com seu conhecimento de maneira ampla.

Se em U1 observa-se uma multiplicidade de abordagens da Psicologia, em U2 nota-se que as quatro disciplinas ofertadas são ministradas partindo de referências base compostas por textos da perspectiva vygotskiana e da humanista. Entretanto, apesar da pouca variedade de abordagens teóricas da Psicologia, o uso destas perspectivas possibilita um olhar 
crítico para a formação do pedagogo ao se levar em consideração o contexto histórico em que irá atuar e a partir disso, refletir sobre como promover a emancipação do sujeito (ASBAHR, 2005),

Percebe-se, ao retomar o quadro 1 , que as universidades de U3 a U6, ofertam uma quantidade menor de disciplinas de Psicologia em seus currículos. U3 possui duas disciplinas obrigatórias e lecionadas nos primeiros anos do curso. As teorias apresentadas são de fundamentos da Análise do Comportamento, Histórico-cultural, Psicanálise e a Epistemologia Genética de Jean Piaget, o que nos permite inferir a possibilidade de apreensão de várias abordagens da Psicologia. Tal ponto corrobora com o perfil do egresso exposto no PPP da instituição, em que almeja um profissional com uma gama de conhecimentos para execução do trabalho pedagógico. Entretanto, com apenas duas disciplinas para contemplar 0 denso conteúdo das abordagens citadas e a breve exposição das diferentes vertentes teóricometodológicas, tal proposta não implica necessariamente uma formação que reflita sobre todo o processo educacional, como adverte Costa (2015).

Além disso, por meio do plano de disciplina de cada disciplina, observa-se que U4 possui praticamente a mesma bibliografia básica em ambas as disciplinas que U3, com algumas diferenças nas indicações complementares, além de compartilharem os mesmos nomes delas. No PPP da U4, como também apresentado por U3, está presente a descrição de um perfil do egresso como profissional crítico, ético e criativo

Já U5, mesmo com as mesmas teorias propostas que as demais instituições, apresenta poucas referências básicas e complementares em seu plano de disciplina, de cada linha, que as demais universidades. O que pode corroborar com maior aprofundamento nas referências utilizadas pela U5, permitindo maior aprimoramento dentro das linhas que se propõe a formação do aluno.

Por intermédio do plano de disciplina, observou-se que a U6 apresenta enfoque nos conteúdos da Análise do Comportamento ministrados na segunda disciplina sobre Psicologia. Entretanto, aglomera linhas teóricas variadas na primeira disciplina ofertada. Nota-se que a U6 se propõe possibilitar a ampliação dos conhecimentos do estudante para que o futuro pedagogo opere seu trabalho em espaços institucionais e que abarquem grupos dos diferentes segmentos da sociedade, como aponta o perfil do egresso da instituição.

\section{Conteúdos ministrados nas disciplinas}

A universidade nomeada como U1 oferece em sua grade curricular a disciplina "Psicologia da Educação: abordagem humanista e epistemologia genética", cujo objetivo é proporcionar as contribuições da Psicologia Humanista e da Epistemologia Genética. Para refletir este processo são abordados os fundamentos teórico-metodológicos da corrente Humanista, os principais conceitos trabalhados dentro desta perspectiva, a relação estabelecida entre desenvolvimento e aprendizagem e ainda as implicações para o processo ensino e aprendizagem. Esta disciplina é oferecida no primeiro ano de graduação, com carga horária de 68 horas e visa proporcionar ao aluno a compreensão da educação a partir de uma perspectiva não difundida tradicionalmente nos cursos de Pedagogia.

No segundo ano do curso de U1, a Psicologia é abordada pela disciplina "Psicologia da Educação: Temáticas da vida contemporânea", cuja carga horária de 34 horas. O objetivo principal é refletir acerca da compreensão e superação de situações discriminatórias e estereótipos, sendo que os temas abordados são indisciplina, gênero e diversidade cultural na educação. Também no segundo ano é oferecida a disciplina "Psicologia da Educação: Abordagens Comportamental e Histórico-Cultural", com o objetivo de possibilitar a compreensão do processo de desenvolvimento e aprendizagem a partir da abordagem Comportamental. São trabalhados os fundamentos teóricometodológicos, os principais conceitos da abordagem comportamental e de que maneira se relacionam com o ensino aprendizagem. Também para os conceitos históricos culturais, a fim de abordar a perspectiva de Vygotsky.

Ainda na mesma universidade, a Psicologia é abordada na disciplina "Psicologia da Educação: Abordagem Walloniana" que possui como objetivo analisar as contribuições da abordagem walloniana no processo de desenvolvimento e aprendizagem. Busca também examinar a interação entre desenvolvimento afetivo e cognitivo e ainda discutir as implicações desta abordagem na prática pedagógica. Estes conceitos são trabalhados a partir da contextualização histórica enquanto sociogênese 
walloniana. São abordados o desenvolvimento humano e a formação de subjetividade, a função das emoções e as dimensões do movimento.

Conforme observado no quadro II, a U2 oferta a disciplina "Psicologia da Educação I", com carga horária de 68 horas, porém, não indica na ementa (como nenhuma das demais) em qual ano do curso está localizada. O objetivo dela é compreender os processos histórico culturais da constituição humana e suas relações com a Psicologia. Os temas trabalhados são: a Psicologia e suas contribuições para o processo educacional, abordando as bases teórico-metodológicas da Psicologia e sua relação com a educação; as formações da psique humana e suas formas particulares de ação sobre o mundo; o desenvolvimento neuro-psico-cultural da criança, do estudante e do adolescente e, ainda, a periodização do desenvolvimento.

O currículo da U2 oferece também a disciplina "Psicologia da Educação II", com carga horária de 68 horas, sendo que não há descrição do ano do curso no qual é lecionada. Os objetivos principais são compreender as abordagens teóricas da Psicologia e suas relações com a educação, estudar o construtivismo piagetiano, a Psicologia Histórico-Cultural e ainda a abordagem da Psicologia Walloniana. Esses conceitos são abordados a partir do conhecimento dos documentos educacionais e sua relação com as teorias psicológicas, no estudo da epistemologia genética de Piaget, na compreensão da Psicologia de Henri Wallon e ainda com a teoria histórico cultural de Vygotsky.

Ainda, a mesma universidade oferece a disciplina "Psicologia da Educação III", com carga horária de 68 horas, cujos objetivos se relacionam à compreensão do desenvolvimento do psiquismo infantil, estudo da formação das funções psicológicas elementares e superiores, compreensão do papel do ensino na formação das funções psíquicas e ainda análise da periodização do desenvolvimento e suas crises, a partir do estudo da relação entre desenvolvimento e aprendizagem, por meio do conceito de mediação na teoria histórico-cultural e na Pedagogia crítica. Estes conceitos também são abordados a partir das dificuldades e distúrbios de aprendizagem.

A última disciplina a discorrer sobre o campo de conhecimento psicológico é "Psicologia da Educação IV", com carga horária de 34 horas. Ela tem como objetivo proporcionar a compreensão dos conceitos de deficiência e eficiência no cenário educativo e na sociedade contemporânea, bem como abordar as diferentes necessidades educativas de pessoas com deficiência e a organização do ensino. Além disso, são discutidas as diferentes deficiências como as físicas, sensoriais, neurológicas e psiquiátricas.

A Psicologia é trabalhada em U3 na disciplina "Psicologia da Educação I" ministrada no primeiro ano do curso com carga horária total de 72 horas. É oferecida no $1^{\circ}$ ano do curso e fornece as bases para compreensão da Psicologia científica, as definições e objetos de estudo, bem como possibilitar o conhecimento histórico da Psicologia da Educação e das teorias do desenvolvimento humano. Estes conceitos são debatidos em cinco unidades: a primeira, aborda a história e constituição da Psicologia, a segunda, Análise do Comportamento e o desenvolvimento no Behaviorismo; a terceira unidade trabalha a epistemologia genética e o desenvolvimento segundo Piaget; a quarta, a Psicologia históricocultural de Vygotsky e a última unidade aborda Freud e o desenvolvimento humano. Os temas abordados, segundo a proposta, proporcionam uma visão geral da Psicologia relacionada ao processo educativo.

No segundo ano do curso, tem-se a disciplina "Psicologia da Educação II", com carga horária de 144 horas, com a proposta de abordar o desenvolvimento neuropsicomotor, cognitivo e emocional, os processos de aprendizagem nas diferentes abordagens teóricas como comportamentalismo, cognitivismo e Psicologia sociocultural. Segundo o plano, visa proporcionar o conhecimento dos fatores que interferem no processo de ensino-aprendizagem a partir da identificação dos problemas e propostas de encaminhamento e ainda as contribuições da Psicologia da educação para a prática educativa. Estes conceitos são desenvolvidos em três unidades: a primeira aborda o sistema nervoso, a aprendizagem e seus desdobramentos, a segunda unidade trata das diferentes teorias de aprendizagem e a terceira e última, a escola, a família e a sociedade.

A universidade identificada como U4 possui em seu currículo a disciplina "Psicologia da Educação I", com carga horária de 72 horas. Na ementa não é descrito em qual ano do curso ela é oferecida. O conteúdo é dividido em cinco unidades: a primeira unidade aborda os conceitos históricos da Psicologia e da Psicologia da educação, discussões sobre psicofisiologia e Psicologia socioeducacional e estudo da 
Psicologia científica. A segunda unidade aborda a Análise do Comportamento, conceituação e o desenvolvimento dos processos, bem como a proposta de educação para o Behaviorismo. A terceira unidade aborda Epistemologia Genética e o desenvolvimento segundo Piaget, o desenvolvimento da estrutura cognitiva (assimilação e acomodação), as fases do desenvolvimento cognitivo e o desenvolvimento moral. A quarta unidade aborda a Psicologia Histórico-cultural de Vygotsky, como o desenvolvimento da linguagem, zonas e níveis de desenvolvimento. A última unidade aborda Freud e o desenvolvimento humano, os conceitos psicanalíticos de organização das estruturas, desenvolvimento humano e organização do trabalho educacional segundo os pressupostos psicanalíticos.

A mesma universidade possui uma disciplina intitulada "Psicologia da Educação II" não especificando em qual ano é trabalhada. Também divide os conteúdos em unidades: a primeira, aborda o sistema nervoso e aprendizagem, ressaltando o desenvolvimento, maturação e crescimento neuromotor, bem como a aprendizagem e suas características; a segunda unidade aborda as teorias da aprendizagem para Asubel, Bruner, Gané, Vygotsky e o modelo de processamento de informações. Na unidade seguinte são trabalhados os conteúdos escola, família e sociedade, com destaque ao papel dos pais no desenvolvimento, formação e aprendizagem. Também faz parte da mesma unidade os princípios norteadores dos papéis dos alunos e professores no processo ensino aprendizagem, as relações sociais e a educação, além das dificuldades, distúrbios e transtornos de aprendizagem.

Conforme o quadro II, U5 oferece a disciplina "Psicologia da Educação: aprendizagem" no primeiro ano do curso, com carga horária de 60 horas. Em seu programa, constam os conteúdos a serem trabalhados: o processo de aprendizagem e sua relação com a Psicologia enquanto relação professor-aluno; os fatores envolvidos nas dificuldades de aprendizagem; a teoria psicanalítica, a teoria behaviorista, a teoria do desenvolvimento cognitivo, a teoria histórico-cultural, e as teorias contemporâneas da motivação para aprender; como também, temas atuais da educação. No segundo ano do curso, a disciplina ministrada é "Psicologia da Educação: desenvolvimento humano", com carga horária de 60 horas. O enfoque tratado nos conteúdos é na Psicologia e o desenvolvimento psicológico nas mesmas abordagens indicadas pela disciplina do ano anterior.

A última universidade a ser analisada, U6 disponibiliza em sua grade curricular a disciplina "Psicologia do Desenvolvimento B". Ela é ministrada no $1^{\circ}$ ano do curso, com carga horária de 120 horas. São trabalhadas a introdução a Psicologia da educação a partir do panorama histórico da Psicologia científica e as contribuições da Psicologia a educação. Também são abordadas as teorias no estudo do desenvolvimento humano como epistemologia genética, psicologia histórico-cultural, teoria psicanalítica e modelo bioecológico.

No terceiro ano é oferecida a disciplina "Psicologia da Aprendizagem A", com carga horária de 72 horas. Os conteúdos trabalhados são a introdução ao Behaviorismo Radical, a teoria social cognitiva de Albert Bandura, considerando os conceitos epistemológicos e princípios básicos. Também são tratados temas como a aprendizagem por processamento de informação a partir da visão construtivista e ainda a teoria da aprendizagem significativa de David Ausubel e os mapas conceituais.

\section{Discutindo a contribuição da Psicologia na formação reflexiva do pedagogo}

A partir da análise dos dados documentais, observa-se que há uma predominância de disciplinas que versam sobre temáticas da Psicologia da Aprendizagem e da Psicologia do Desenvolvimento, embasadas em diferentes correntes teórico-metodológicas, pluralidade que é muito presente no âmbito da Psicologia. Embora estas diferentes vertentes da Psicologia possibilitem um olhar amplo sobre os diversos fatores que concorrem para o processo educacional, a carga horária total das disciplinas pesquisadas apresenta uma variação grande entre as universidades, com a menor carga possuindo 102 horas (U1) e a maior, 230h (U2). Esse dado mostra o risco de que, em vista da diversidade de conceitos e teorias psicológicas a serem ministradas com uma carga horária reduzida, ocorra uma fragmentação dos conteúdos ou mesmo um trabalho superficial, conduzindo a uma análise reducionista sobre a relação Psicologia e Educação, sem compreender o fenômeno subjetivo em sua complexidade. 
Considera-se importante e necessário ampliar o olhar sobre a complexidade de relações e forças que envolvem o campo da educação. Para tanto, dar visibilidade para os interesses hegemônicos que são ocultados, os jogos de poder, os efeitos das políticas educacionais, o funcionamento da instituição escola, a normalização de comportamentos, a homogeneização dos alunos, o controle, a vigilância, a exclusão que ocorre na inclusão se faz necessário (PATTO, 2005; VEIGA-NETO, 2000; FREIRE,1987). Desta maneira, é imprescindível que a Psicologia explicite o desenvolvimento humano e a aprendizagem não tomados de forma isolada, como um processo natural e universal, mas em interlocução com o campo social, econômico e político, evidenciando que o processo educacional é multideterminado.

Nesse sentido, há uma grande preocupação com os caminhos oferecidos pelos referenciais teóricos da Psicologia da Educação e com as práticas que são por eles legitimadas. Torna-se relevante a investigação das possibilidades de uma práxis educativa emancipatória, possibilitada pelos conteúdos teórico-práticos oferecidos por tal campo do conhecimento (TONUS, 2006, p.2), de modo a proporcionar a formação de sujeitos (e, portanto, profissionais) reflexivos, protagonistas de sua própria história e agentes de transformação social.

Dentre as temáticas da Psicologia presentes das disciplinas analisadas, algumas delas podem contribuir para uma reflexão crítica sobre o processo educacional como possibilidade de emancipação e inclusão. Notou-se a presença de temas como a diversidade cultural, questões de gênero, compreensão e superação da discriminação, do preconceito e da construção de estereótipos (conteúdos agrupados na disciplina denominada "Temáticas da vida contemporânea" - U1); as contribuições da Psicologia para o processo educacional, abordando as bases teórico-metodológicas da Psicologia e sua relação com a educação, a compreensão dos conceitos de deficiência e eficiência no cenário educativo, bem como abordar as diferentes necessidades educativas de pessoas com deficiência e a organização do ensino (U2); os fatores sociais e políticos que interferem na aprendizagem, e a problematização sobre as avaliações e a medicalização (como presentes em U4) e o ensino de uma perspectiva interdisciplinar e multimetodológica do desenvolvimento humano, além da inclusão de questões contemporâneas e sua relevância social (observado em U6).

Há que se considerar os limites entre aprender os conteúdos de Psicologia e a aplicação desses conhecimentos. Tal lacuna, por exemplo, poderia ser preenchida com o oferecimento de disciplinas práticas, sendo que estas poderiam possibilitar uma maior contextualização dos conceitos e contribuições da Psicologia ao exercício profissional do pedagogo. Assim, ao articular teoria e prática a partir da realidade cotidiana, evita-se uma visão rasa da Psicologia. Para tanto, faz-se necessário um trabalho em rede, multi e interdisciplinar na operacionalização do currículo, para trabalhar essa interface entre os campos. Entretanto, dentre as universidades analisadas, apenas U5 e U6 vê-se a presença de uma quantidade de horas práticas para cada disciplina.

Quanto ao perfil dos egressos e a análise dos Projetos Políticos Pedagógicos das instituições de ensino, percebe-se que em larga medida, preconiza-se uma formação com compromisso ético e social. Necessita-se, assim, que a formação desse profissional possibilite uma análise crítica sobre a realidade e o fenômeno complexo da educação, além da capacidade de intervir e fazer articulações entre a educação e o contexto social e político, com vistas a promoção de cidadãos reflexivos.

\section{CONSIDERAÇÕES FINAIS}

A Psicologia, a Pedagogia e a Educação são saberes produzidos pelo humano que está em movimento, devendo ser constantemente repensadas em suas articulações sociopolíticas e desdobramentos. Isto pois, o uso indevido desses saberes pode justificar e legitimar a desigualdade, a segregação e a exclusão social, como pôde ser constatado na história, na imbricação da Psicologia com a Educação.

Nesse sentido, o objetivo deste trabalho foi levantar e compartilhar como a Psicologia é inserida em alguns cursos de formação de Pedagogia. Para tanto, destacando a necessidade de inserção de temáticas e disciplinas da Psicologia que discorram sobre a educação como processo complexo e multideterminado. A Psicologia pode contribuir com o futuro educador para uma reflexão crítica sobre a realidade social, a educação e a instituição escola, suas demandas e as problemáticas contemporâneas, incidindo numa formação voltada para a emancipação e transformação social. Para tanto, precisa se 
aproximar do contexto histórico e social dos seus atores, com a colaboração de uma equipe interdisciplinar para compreensão e intervenção.

Destarte, ao analisar alguns componentes dos cursos de Pedagogia das universidades estaduais do Norte do Paraná, notou-se a multiplicidade de temas nas disciplinas de Psicologia inseridas nos planos de disciplina. Além disso, a variabilidade de linhas teóricas da Psicologia ofertadas nos planos de disciplina das instituições, o que podem promover uma maior amplitude do olhar do pedagogo, desde que sejam entrelaçadas com uma discussão ética e social mais ampla, como preconizada nos PPPs. Contudo, observou-se a necessidade de futuras pesquisas aprofundarem, de maneira minuciosa, sobre as linhas teóricas disponibilizadas e suas implicações para o exercício profissional, como também, se conduzem aos objetivos indicados pelos projetos formativos.

Entende-se que a Psicologia pode participar da formação reflexiva do pedagogo a partir da análise dos fatores envolvidos no campo educacional e dos seus entraves sociopolíticos, assim oportunizando a promoção da emancipação dos futuros pedagogos para que eles formem cidadãos com seu ofício. Porém, o modo de sua presença e operacionalização é que poderá garantir tal contribuição para formação dos educadores, o que coloca desafios para as instituições e equipes formadoras.

\section{REFERÊNCIAS}

ALMEIDA, P. C. A.; AZZI, R. G. A psicologia da educação como um saber necessário para a formação de professores. Temas em psicologia, Ribeirão Preto, v. 15, n. 1, p. 41-55, jun. 2007. Disponível em: http://pepsic.bvsalud.org/scielo.php?script=sci_a rttext\&pid=S1413-

$389 \times 2007000100006 \& \operatorname{lng}=p t \& n r m=i s o . \quad$ Acesso em: 18 jun. 2018.

ANTUNES, M. A. M. Psicologia Escolar e Educacional: história, compromissos e perspectivas. Psicologia Escolar e Educacional, v. 12, n. 2, p. 469-475, 2008. Disponível em: http://www.scielo.br/scielo.php?script=sci_arttex $\mathrm{t} \& \mathrm{pid}=\mathrm{S} 1413-85572008000200020$. Acesso em: 15 abr. de 2018.

ASBAHR, F. S. F. Sentido pessoal e projeto político pedagógico: análise da atividade pedagógica a partir da psicologia histórico- cultural. f. 199, 2005. Dissertação (Doutorado em P). Universidade de São Paulo, São Paulo, 2005.

ALVES, R. dos S. L. A (a)normalidade como discurso a partir da análise das disciplinas de Psicologia nos cursos de Pedagogia das universidades públicas do Paraná. $f, 112$. 2016.Dissertação (Mestrado em Psicologia) Universidade Estadual de Maringá, Maringá, 2016.

BRANDÃO, C. R. O Que é Educação. São Paulo: Editora Brasiliense, 1981. Disponível em: http://www.aedi.ufpa.br/parfor/letras/images/d ocumentos/ativ1_2014/abaetetuba/moju2012/fu ndamentos\%20da\%20educao\%20_\%20profa.\%20 suzana\%20moura_texto.pdf. Acesso em: 06 abr de 2018.

BRASIL. Ministério da Educação. Lei de diretrizes e bases da educação nacional. Brasília: Senado Federal, Coordenação de Edições Técnicas, 2017. 58 p. Disponível em: http://www2.senado.leg.br/bdsf/bitstream/hand le/id/529732/lei de diretrizes e bases 1ed.pdf. Acesso em 01 dez. 2018.

CARVALHO, D. C. A psicologia frente a educação e o trabalho docente. Psicologia em Estudo, Maringá, v. 7, n. 1, jun. 2002. Disponível em http://www.scielo.br/pdf/\%0D/pe/v7n1/v7n1a06 .pdf. Acesso em: 09 maio 2018.

CECHINEL, A et al. Estudo/Análise Documental: Uma Revisão Teórica e Metodológica. Criar Educação, PPGE, UNESC, Criciúma, v. 5, n. 1, jan./jun., 2016. Disponível em: periodicos.unesc.net/criaredu/article/download/ 2446/2324. Acesso em: 24 março 2018.

COLINVAUX, D.; BANKS-LEITE, L. E. Claparède: os primeiros estudos sobre a psicologia das crianças pequenas no Institut Jean-Jacques Rousseau. ProPosições, Campinas, v. 23, n. 2, p. 217-220, Aug. 2012. DOI: $10.1590 /$ S0103-73072012000200014 Disponível em: http://www.scielo.br/scielo.php?script=sci_arttex t\&pid=S0103-

$73072012000200014 \&$ Ing=en\&nrm=iso. Acesso em: 09 jul 2018.

COSTA, C. R. Psicologia e Formação do Pedagogo: análise da disciplina Psicologia da 
Educação na UFG/RC (1988/2014) [manuscrito] 2015. 146, CXLVI f. Disponível em: http://repositorio.bc.ufg.br/tede/bitstream/tede /5061/5/Disserta\%C3\%A7\%C3\%A30\%20\%20Cibele\%20dos\%20Reis\%20Costa\%20\%202015.pdf. Acesso em: 15 abr. 2018.

ENGELS, F. O papel do trabalho na transformação do macaco em homem. Revista Trabalho Necessário, v. 4, n. 4, 2006. DOI: 10.22409/tn.4i4.p4603. Disponível em: http://periodicos.uff.br/trabalhonecessario/articl e/view/4603. Acesso em 10 jul. 2018.

FREIRE, Paulo. Pedagogia do oprimido. 17. ed. Rio de Janeiro: Paz e Terra, 1987. V.3.

LIBÂNEO, J. C. Didática. São Paulo: Cortez, 2006.

LIMA, A. L. G.; CATANI, D. B. "Que tipo de aluno é esse?": psicologia, pedagogia e formação de professores. Revista Brasileira de Educação, v. 20 , n. 62 , p. 571-593, 2015. DOI: 10.1590/S141324782015206202. Disponível em: http://www.scielo.br/scielo.php?script=sci_arttex t\&pid=S1413-

$24782015000300571 \&$ lng=pt\&tlng=pt. Acesso em 27 mar. 2018.

LIMA, E. C. A. S. O conhecimento psicológico e suas relações com a educação. Em Aberto, v. 9, n. 48 , 1990.

http://emaberto.inep.gov.br/index.php/emabert o/article/view/1787/1758. Acesso em 11 jul 2018.

MARTINS, L. M. Pedagogia histórico-crítica e psicologia histórico cultural. Araraquara: UNESP, 15 dez. 2011. Palestra proferida no evento comemorativo aos 30 anos da Pedagogia histórico-crítica.

MOREIRA, A.F.B. A psicologia e o resto: o currículo segundo César Coll. Cadernos de Pesquisa, n. 100, São Paulo, p. 109-120, mar. $1997 . \quad$ Disponível em: http://publicacoes.fcc.org.br/ojs/index.php/cp/ar ticle/view/770/782. Acesso: 24 abr. 2018.

PATTO, M. H. S. Exercícios de indignação: escritos de educação e psicologia. São Paulo: Casa do Psicólogo. 2005.
PEREIRA, E.; MARTINS, J. R.; ALVES, V. S.; DELGADO, E. I. A contribuição de John Dewey para a educação. Revista Eletrônica de Educação, v. 3, n. 1, p. 154-161, 2009. http://www.reveduc.ufscar.br/index.php/revedu c/article/view/38/37. Acesso 11 jul 2018.

PETERNELLA, A.; GALUCH, M. T. B. A relação teoria e prática na formação inicial do pedagogo na perspectiva da psicologia histórico-cultural. InterMeio: revista do Programa de PósGraduação em Educação, Campo Grande, v. 17, n. 34, p.13-28, jul./dez. 2011. Disponível em: http://www.seer.ufms.br/index.php/intm/article /view/2390/1513. Acesso em: 14 abr. 2018.

SAVIANI, D. Escola e Democracia. 41. ed. Campinas-SP: Autores Associados, 2009.

SOUZA, M.P. R. Psicologia Escolar e Educacional em busca de novas perspectivas. Revista Semestral da Associação Brasileira de Psicologia Escolar e Educacional (ABRAPEE), v.13, n.1, Janeiro/Junho 2009. Disponível em:

http://pepsic.bvsalud.org/pdf/pee/v13n1/v13n1a 21.pdf. Acesso em: 15 abr. 2018.

TONUS, Karla PAULINO. A psicologia e a educação para a emancipação: contribuições do pensamento crítico. Revista Científica Eletrônica de Psicologia. V.6, n.6, maio/2006. Disponível em:

http://faef.revista.inf.br/imagens_arquivos/arqui vos_destaque/Mo21mIUCu9WZXFX_2013-4-3016-44-11.pdf. Acesso em: 24 nov. 2018.

VEIGA, I. P. A. Inovações e projeto políticopedagógico: uma relação regulatória ou emancipatória? Cadernos CEDES, v. 23, n. 6, p. 267- 281, 2003. DOI: 10.1590/S010132622003006100002 . Disponível em: http://www.scielo.br/scielo.php?script=sci_arttex $\mathrm{t} \& \mathrm{pid}=\mathrm{S} 0101-$

$32622003006100002 \& \operatorname{lng}=p t \& t \operatorname{lng}=p t . \quad$ Acesso em: 27 mar. 2018.

VEIGA-NETO, A. Espaços, tempos e disciplinas: as crianças ainda devem ir à escola. Linguagens, espaços e tempos no ensinar e aprender, v. 2, p. 09-20, 2000. Disponível em: http://www.lite.fe.unicamp.br/cursos/nt/ta5.4.ht m. Acesso em: 18 jun. 2018. 
VYGOTSKY, L. S. Manuscrito de 1929. Educação \&

Sociedade, v. 21, n. 71, p. 21-44, 2000. Disponível em: http://www.scielo.br/scielo.php?pid=S0101$73302000000200002 \&$ script=sci_arttext\&tlng=pt. Acesso em: 10 jul. 2018.

Recebido para avaliação: 13/07/2018

Revisado em: 02/12/2018

Aceite Final: 03/12/2018 